\title{
Antioxidant and Anti-inflammatory Properties Mediate the Neuroprotective Effects of Hydro-ethanolic Extract of Tiliacora triandra Against Cisplatin-induced Neurotoxicity
}

\author{
Yanping Huang ${ }^{1, *}$ \\ Chunhong Liu ${ }^{2, *}$ \\ Xianbing Song' \\ Mei An' \\ Meimei Liu' \\ Lei Yao'
}

Ademola C Famurewa ${ }^{3}$

Opeyemi Joshua Olatunji (1D ${ }^{4}$

'Department of Human Anatomy, Histology and Embryology, Anhui Medical College, Hefei, 23060I, People's Republic of China; ${ }^{2}$ Second Peoples Hospital of Wuhu City, Wuhu, 24I00I, Anhui, People's Republic of China; ${ }^{3}$ Department of Medical Biochemistry, Faculty of Basic Medical Sciences, Alex Ekwueme Federal University, Ndufu Alike Ikwo, Ebonyi State, Nigeria; ${ }^{4}$ Faculty of Thai Traditional Medicine, Prince of Songkla University, Hat Yai, 901 I0, Thailand

*These authors contributed equally to this work
Correspondence: Chunhong Liu Second Peoples Hospital of Wuhu City, Wuhu, 24I00I, Anhui, People's Republic of China

Email18155317015@163.com

Opeyemi Joshua Olatunji Faculty of Thai Traditional Medicine, Prince of Songkla University, Hat Yai, 90110, Thailand

Email opeyemi.j@psu.ac.th
Background: Cisplatin (CDDP) is an efficacious anticancer agent used widely in chemotherapy despite its severe side effect related to neurotoxicity. Redox imbalance and inflammatory mechanism have been implicated in the pathophysiology of CDDP-induced neurotoxicity. Herein, we investigated whether Tiliacora triandra (TT) extract could inhibit CDDP-induced redox-mediated neurotoxicity and behavioural deficit in rats.

Materials and Methods: CDDP-induced redox-mediated neurotoxicity and behavioral deficit in rats. Rats were administered TT for five consecutive weeks $(250$ and $500 \mathrm{mg} / \mathrm{kg}$ bw), while weekly i.p. injection of CDDP commenced on the second week ( $2.5 \mathrm{mg} / \mathrm{kg} \mathrm{bw})$ of the TT administration.

Results: CCDDP caused significant body weight reduction and cognitive diminution as revealed by Morris water maze and Y maze tests. In the CDDP-induced cognitive impairment (CICI) rats, there were remarkable increases in the brain levels of TNF- $\alpha$, IL- 6 and IL$1 \beta$ and malondialdehyde (MDA), whereas catalase (CAT), glutathione (GSH), glutathione peroxidase (GPx) and superoxide dismutase (SOD) activities considerably decreased compared to normal control. The brain acetylcholinesterase (AChE) activity in CDDP control rats was significantly increased compared to the normal control. The expression of caspase- 3 and 553 proteins was upregulated by CDDP injection, whereas $\mathrm{Bcl} 2$ was downregulated coupled with histopathological alterations in the rat brain. Interestingly, treatment with TT significantly abated neurobehavioral deficits, MDA and cytokine levels and restored CAT, GPx, GSH, SOD, and AChE activities compared to the CDDP control rats. Caspase- 3 level as well as $\mathrm{Bcl} 2$ and $\mathrm{p} 53$ expressions were modulated with alleviated changes in histopathology.

Conclusion: The findings highlight neuroprotective and cognitive function improvement efficacy of TT against CICI via redox-inflammatory balance and antiapoptotic mechanism in rats.

Keywords: Tiliacora triandra, cisplatin, neurotoxicity, oxidative stress, inflammation

\section{Introduction}

Cancer is one of the major causes of global mortality, accounting for more than nine million deaths in 2018. The gruesome burden including financial, physical, and emotional stress associated with cancer is growing at an exponential rate especially in low and middle-income countries with little or no adequate resources to manage the burden. As such, rigorous efforts have been invested into developing several 
therapies that can increase the survival and improve the quality of life of cancer patients. ${ }^{1}$ Chemotherapy is one widely used approach for treating cancers and tumors and several anticancer drugs have been developed and approved including cyclophosphamide, doxorubicin, cisplatin, vincristine among others. ${ }^{2-4}$

Cisplatin, a platinum-based anticancer drug is a major and widely used drug for treating several malignancies such as head and neck, testicular, and non-small-cell lung cancer. ${ }^{5,6}$ In spite of the relative success attained by cisplatin, its applicability has been extremely curtailed due to a number of serious side effects including ototoxicity, renal toxicity, testicular toxicity, and neuronal toxicity. ${ }^{7,8}$ Cisplatin-induced cognitive impairment (CICI) also known as "chemobrain" encompasses a wide range of features including reduction in processing speed, learning and memory dysfunction, and loss of locomotive activity. ${ }^{1,9} \mathrm{At}$ present the pathophysiology of CICI is yet to be fully comprehended, thus making effective treatment for patients a daunting task. However, multiple pathophysiological mechanisms have been postulated to decipher CICI including oxidative stress, inflammation, mitochondrial dysfunction, DNA damage and apoptosis. ${ }^{10,11}$ Unfortunately, there are no effective therapies for mitigating CICI, and as such it is imperative to consider alternative treatment that can interfere with the proposed underlying mechanism associated with CICI.

Tiliacora triandra (TT) is an edible vegetable and herbal plant used for treating malaria, diabetes, fever, and as a detoxification agent. TT possesses multiple pharmacological properties such as antidiabetic, antimicrobial, antioxidant, antimalaria, and neuroprotective effects. ${ }^{12-14}$ The application of TT as a neuroprotective agent has been previously explored. The extracts from the leaves of the plant enhanced memory and learning as well as prevented neuronal death in models of cerebral ischemia/reperfusion. In addition, TT enhanced antioxidative enzymes and reduced acetylcholinesterase activity in ethanol dependence animals. ${ }^{13,15-17}$ However, the protective effects of TT against CICI is unknown and unexplored. In this work, the protective effects of TT extract against CDDP induced $\mathrm{CICI}$ in rats was explored.

\section{Materials and Methods}

\section{Plant Specimen}

The collection of $T$. triandra as well as the preparation of TT extract was according to a previous study. ${ }^{18}$ Briefly, the leaves were washed, oven dried, powdered and $200 \mathrm{~g}$ of the powder was macerated in $2 \mathrm{~L}$ of $70 \%$ ethanol on a shaker for $24 \mathrm{~h}$. Thereafter, the extract was filtered and concentrated to one third of its original volume and kept at $4^{\circ} \mathrm{C}$ overnight. The solution was decanted, centrifuged, and lyophilized to obtain a light brown hydroscopic powder (TT), which was stored in an airtight container at $4^{\circ} \mathrm{C}$ until use.

\section{UHPLC-DAD-ESI-QTOF-MS Profiling of TT Extract}

The identification of bioactive metabolites in TT extract was performed using UPLC-ESI-Q-TOF-MS analysis. Briefly, $50 \mathrm{mg}$ of $\mathrm{TT}$ was dissolved in $1 \mathrm{~mL}$ of $50 \%$ methanol, centrifuged and the supernatant obtained was filtered using $0.22 \mu \mathrm{m}$ nylon membrane. The extract subjected to UHPLC-ESI-QTOF-MS analysis.

\section{Animals}

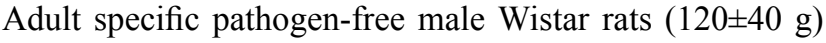
were used in this study. The rats were kept in stainless steel cages with six rats per cage and housed in a well ventilated animal house facility. The rats were given continuous access to tap water and normal rat food for one week before the commencement of the study. The study was approved by the Ethics Committee of Anhui Medical College (ethic approval number: Anhuiyxgdzkxx-202007008) and followed, the guidelines of the US National Institute of Health for the Care and Use of Laboratory Animals (NIH, revised 1978).

\section{Experimental Design}

After the seven days of adaptation, the rats were randomized into four groups as follows:

(I) Healthy control rats (HNC): administered with normal saline.

(II) CDDP control rats (CDDP): administered with normal saline.

(III) TT-250-treated rats: administered with $250 \mathrm{mg} / \mathrm{kg}$ of TT extract.

(IV) TT-500-treated rats: administered with $500 \mathrm{mg} / \mathrm{kg}$ of TT extract.

The rats in the TT-250 and TT-500 groups were given TT on a daily basis for 35 days and were simultaneously given a weekly i.p. injection of $2.5 \mathrm{mg} / \mathrm{kg}$ of CDDP for 
four weeks, beginning on the second week of TT administration. Likewise, the CDDP control rats received a weekly i.p. injection of CDDP $(2.5 \mathrm{mg} / \mathrm{kg})$ for four weeks from the second week of normal saline administration (Figure 1). The choice of TT dose was adopted from previous studies. ${ }^{12,13,18}$ The animals were subjected to behavioral studies upon completion of the treatment.

\section{Behavioral Studies Morris Water Maze Test}

The method used for the Morris water maze (MWM) test was according to previous report. ${ }^{19}$ A circular pool-like container with the following dimensions was used for the MWM test: diameter of $150 \mathrm{~cm}$ and a height of $40 \mathrm{~cm}$, with water depth of $30 \mathrm{~cm}$. The water was made opaque with milk powder and a hidden platform was placed $1 \mathrm{~cm}$ below the surface of the water. The rats were trained individually on day 0 prior to the start of the experiment. The acquisition trail was conducted on days $1-4$, while the fifth day was the exploration period. For the training and acquisition trail, the rats were gently placed into the pool along the walls of the four different arbitrary quadrants and gently released with their heads raised up to swim and locate the position of the hidden platform within 60 seconds. The time taken for the rats to locate the submerged platform before the expiration of the 60 seconds was recorded. The rats that were unable to locate the platform within 60 seconds were gently guided to the position of the platform and allowed to stay on the platform for 10 seconds. On the fifth day the platform was removed and the time that each rat stayed in the target quadrant where the platform was previously placed was recorded within 60 seconds.

\section{Y Maze Test}

The Y maze test was used to evaluate spontaneous alternation of recognition using a previously described method. ${ }^{20}$ The maze was made up of three identical arms $\mathrm{X}, \mathrm{Y}$, and $\mathrm{Z}$ with dimensions of $35 \mathrm{~cm}$ long, $30 \mathrm{~cm}$ high, and a width of $15 \mathrm{~cm}$, stationed at equal angles. The rats were introduced into the maze from the end of one arm and allowed to freely navigate through the maze within five minutes. Spontaneous alternation was evaluated by visually recording the pattern of complete entry into each arm (the rat's hind paws goes entirely into the arm). The frequency of alternation into the arms was recorded based on successive entries into the three arms on overlapping triplet sets (XYZ, YZX, ZXY).

\section{Animal Sacrifice}

Following the behavioral studies, the rats were euthanized with pentobarbital sodium and the brain tissues were carefully removed from the cranium, washed with normal

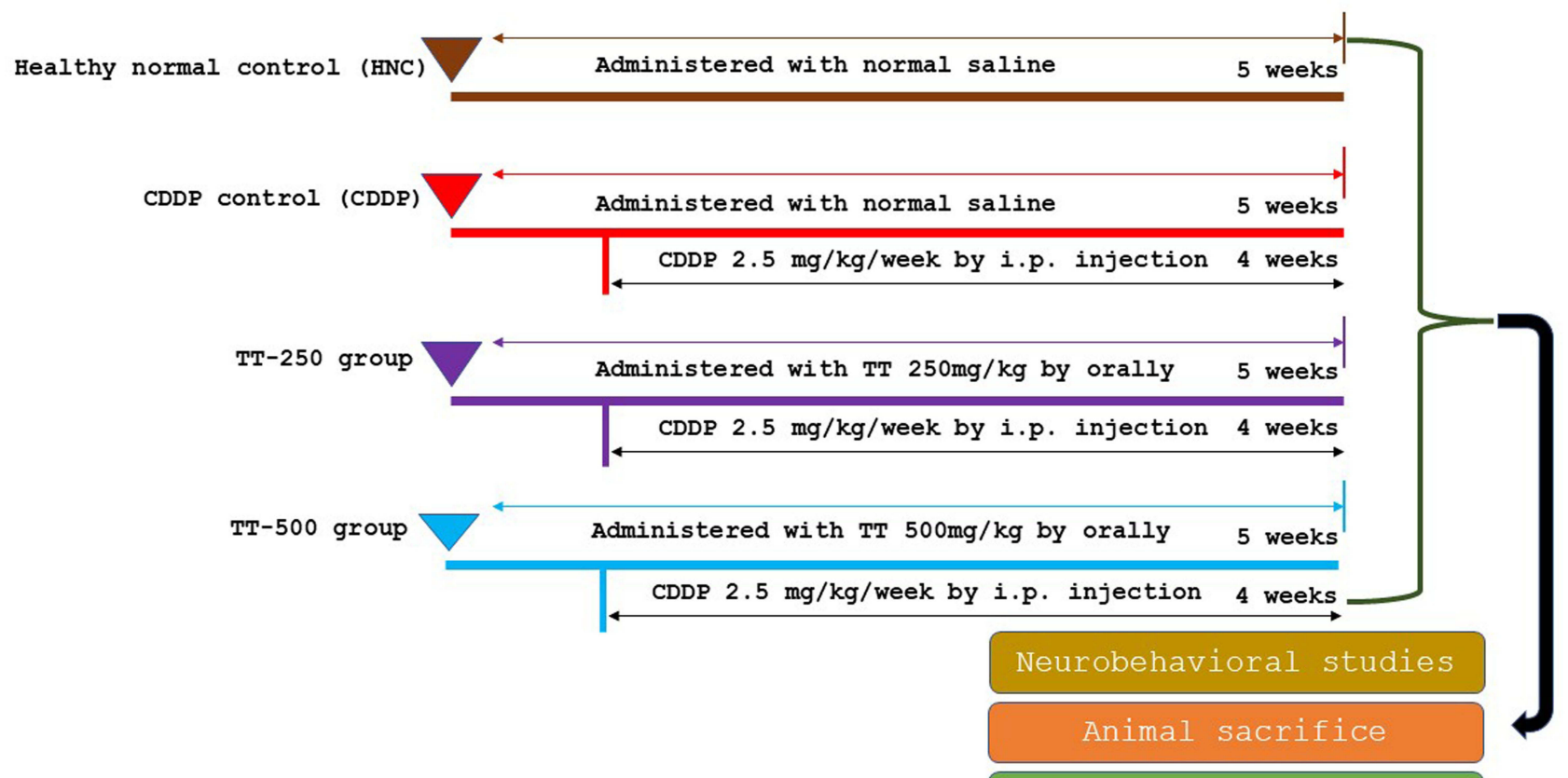

Biochemical studies

Figure I Experimental design and animal grouping. 
saline to remove residual blood, and weighed. Some part of the brain tissues was kept in $10 \%$ buffered formalin solution for histopathologic analyses using routine hematoxylin and eosin (H\&E) staining techniques. The remaining portion of the brain tissues was homogenized in icecold $0.1 \mathrm{M}$ phosphate buffer ( $\mathrm{pH}$ 7.4) and thereafter subjected to high speed centrifugation and the resulting brain tissue supernatant was used in the determination of biochemical analyses.

\section{Evaluation of Biochemical Parameters in the Brain}

Oxidative stress parameters including lipid peroxidation products malondialdehyde (MDA), superoxide dismutase (SOD), catalase (CAT), glutathione (GSH) and glutathione peroxidase (GPx) activities in the brain homogenates were assayed using assay kits from Nanjing Bioengineering Institute, China. Moreover, the levels of TNF- $\alpha$, IL- 6 , IL$1 \beta$ and caspase- 3 were assayed with ELISA kits from Abcam (Cambridge, UK). Acetylcholinesterase (AChE) activity was determined using the previously reported method. ${ }^{21}$

\section{Histology}

Brain histological examination was performed on $4-5-\mu \mathrm{m}$ tissue sections stained with hematoxylin and eosin using standard protocol.

\section{Immunohistochemistry}

Immunostaining of the brain tissues for the expression of $\mathrm{Bcl} 2$ and $\mathrm{p} 53$ proteins were performed following previously reported method. ${ }^{22}$ Quantitative analysis of the immunostained intensity of $\mathrm{Bcl} 2$ and p53 proteins was performed using image $\mathrm{J}$ software.

\section{Statistical Evaluation}

All data are shown as mean $\pm \mathrm{SD}$ and analyzed using one-way ANOVA with Tukey's HSD multiple range post hoc test using GraphPad Prism version 5. Data was considered statistically significant at $p<0.05, p<0.01$ or $p<0.001$.

\section{Results}

\section{TT Ameliorated CDDP-triggered Weight Loss}

The body weight of the rats were not significantly different at the beginning of the experiment prior to CDDP injection. Whereas, the weight of the CDDP control rats was significantly reduced by the end of the experiment compared to the HNC rats (Figure 2). In contrast, TT significantly prevented body weight loss in the treated groups compared to the CDDP group. Moreover, the weight of the brain of the rats in the CDDP group was observed to be lower than the HNC and TT treated groups (Figure 2).

\section{TT Alleviated CDPP Induced Cognitive Dysfunction in Rats}

In the MWM test, the latency time of rats in the CDDP control group to locate the hidden platform was significantly increased compared to the $\mathrm{HNC}$ rats throughout the
A

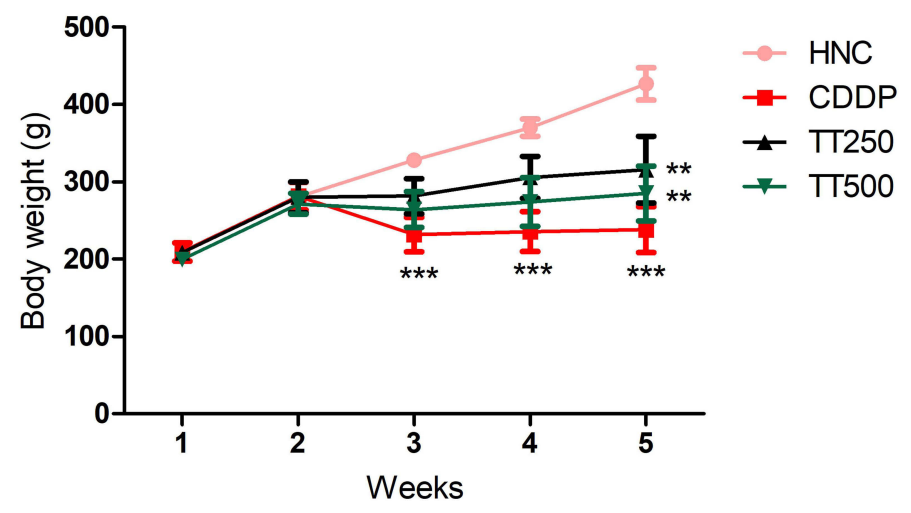

B

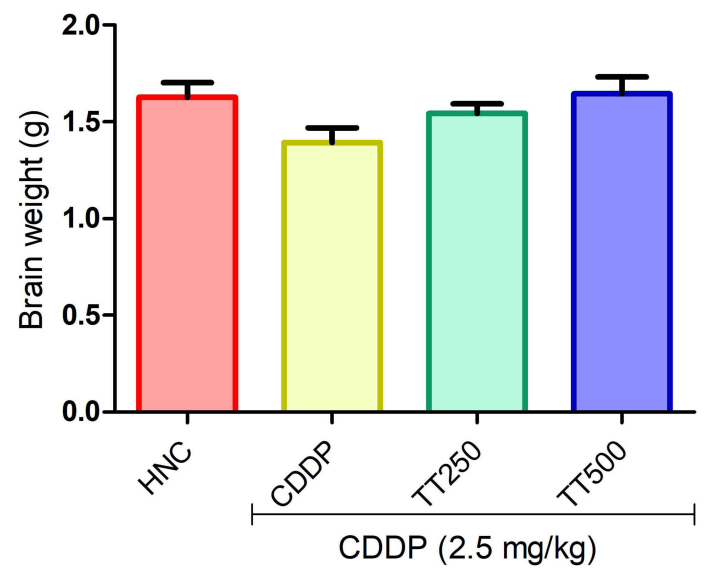

Figure 2 Effect of TT on (A) body and (B) brain weight in CDDP induced neurotoxicity in rats. Results are expressed as mean \pm SD ( $\mathrm{n}=6$ ) and analyzed using one way ANOVA followed by Tukey's post hoc test. $*_{p}<0.00$ I indicates significant difference compared to HNC group; $*^{*} p<0.00 \mathrm{I}$ indicates significant difference compared to CDDP group. 
A

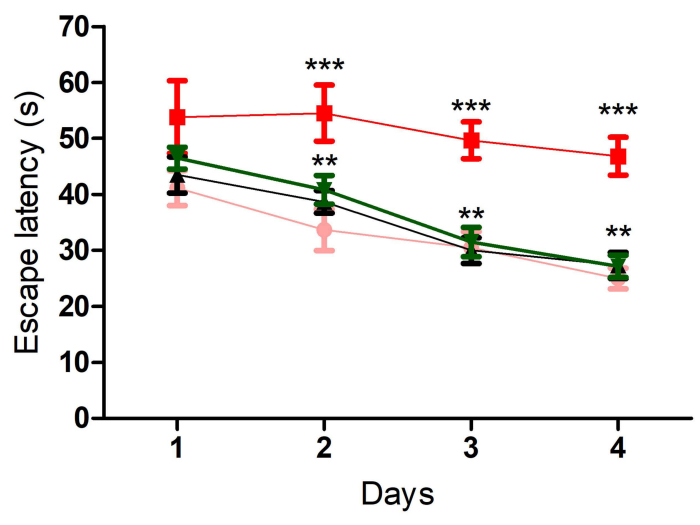

B

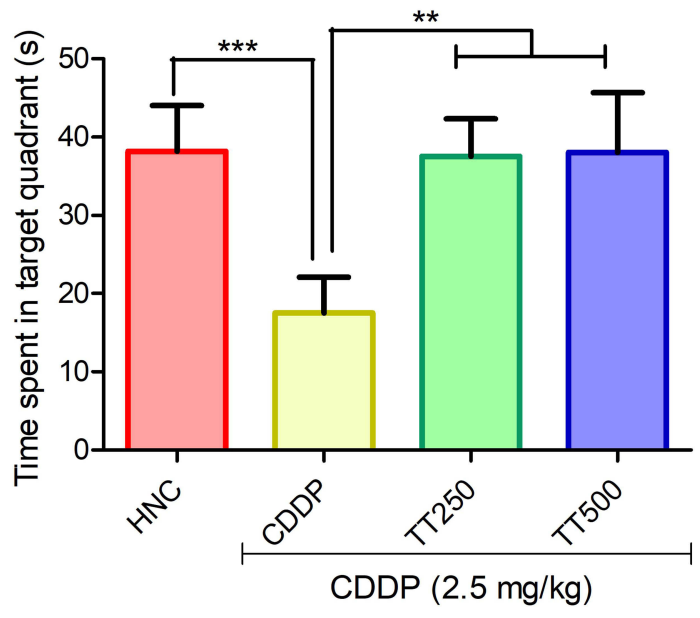

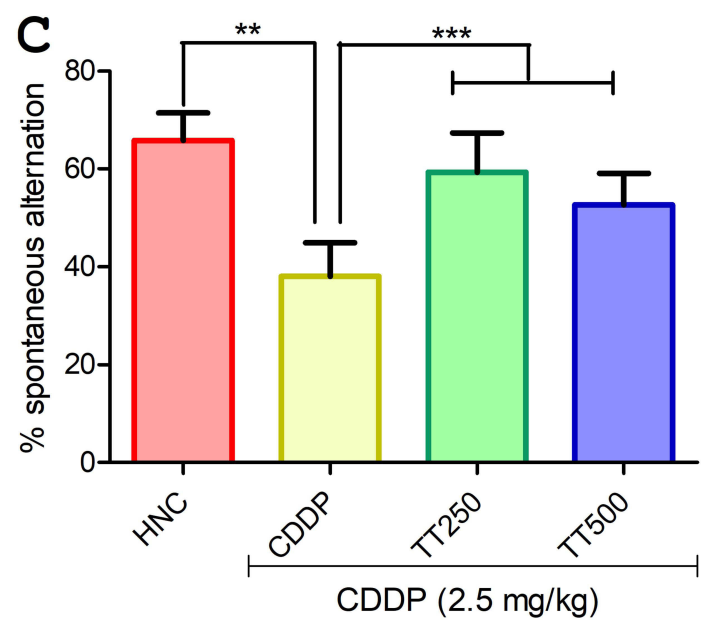

Figure 3 Effect of TT on neurobehavioral parameters in CDDP induced neurotoxicity in rats. (A and B) Morris water maze test (C) $Y$ maze test. Results are expressed as mean $\pm S D(n=6)$ and analyzed using one-way ANOVA followed by Tukey's post hoc test. $* p<0.00$ I indicates significant difference compared to HNC group; $* *<<0.00$ I indicates significant difference compared to CDDP group.

acquisition trial period $(p<0.001$; Figure $3 \mathrm{~A})$. In contrast, the time taken by the rats in the TT-treated group was observed to be significantly shortened from day two of the acquisition trial compared to the CDDP control animals (Figure 3A). In addition, in the exploration test, the CDDP control rats showed shorter retention memory as observed by significant reduction in the time spent in the target quadrant compared to the HNC and TT-treated groups, suggesting decreased spatial memory in CDDP control rats $(p<0.001$; Figure 3B). Furthermore, in the Y-maze test, the CDDP control rats showed significantly reduced percentage spontaneous alternation compared to $\mathrm{HNC}$ group ( $p<0.001$; Figure $3 \mathrm{C}$ ), but the rats in the TT-treated groups showed significant increase in the percentage spontaneous alternation when compared to the untreated CDDP control rats $(p<0.001$; Figure $3 \mathrm{C})$.

\section{TT Attenuated CDDP-induced Oxidative Stress in the Brain of Rats}

Figure 4 portrays the effects of TT on oxidative stress indices in the brain of the experimental rats. The administration of CDDP elicited significant increase in MDA levels in the CDDP control rats in comparison with HNC group ( $p<0.001$; Figure 4A). However, treatment with TT markedly abated MDA levels compared to CDDP control rats $(p<0.001$; Figure 4A). In addition, Figure 3B-E depicts the effect of TT on antioxidant enzymes activities in the brain of experimental rats. The activities of brain GPx, SOD, GSH, and CAT in CDDP control animals were markedly reduced compared with the HNC group. Treatment with TT upregulated the activities of these antioxidative enzymes in the brain tissues in comparison with CDDP control group ( $p<0.001$; Figure $4 \mathrm{~B}-\mathrm{E})$. 

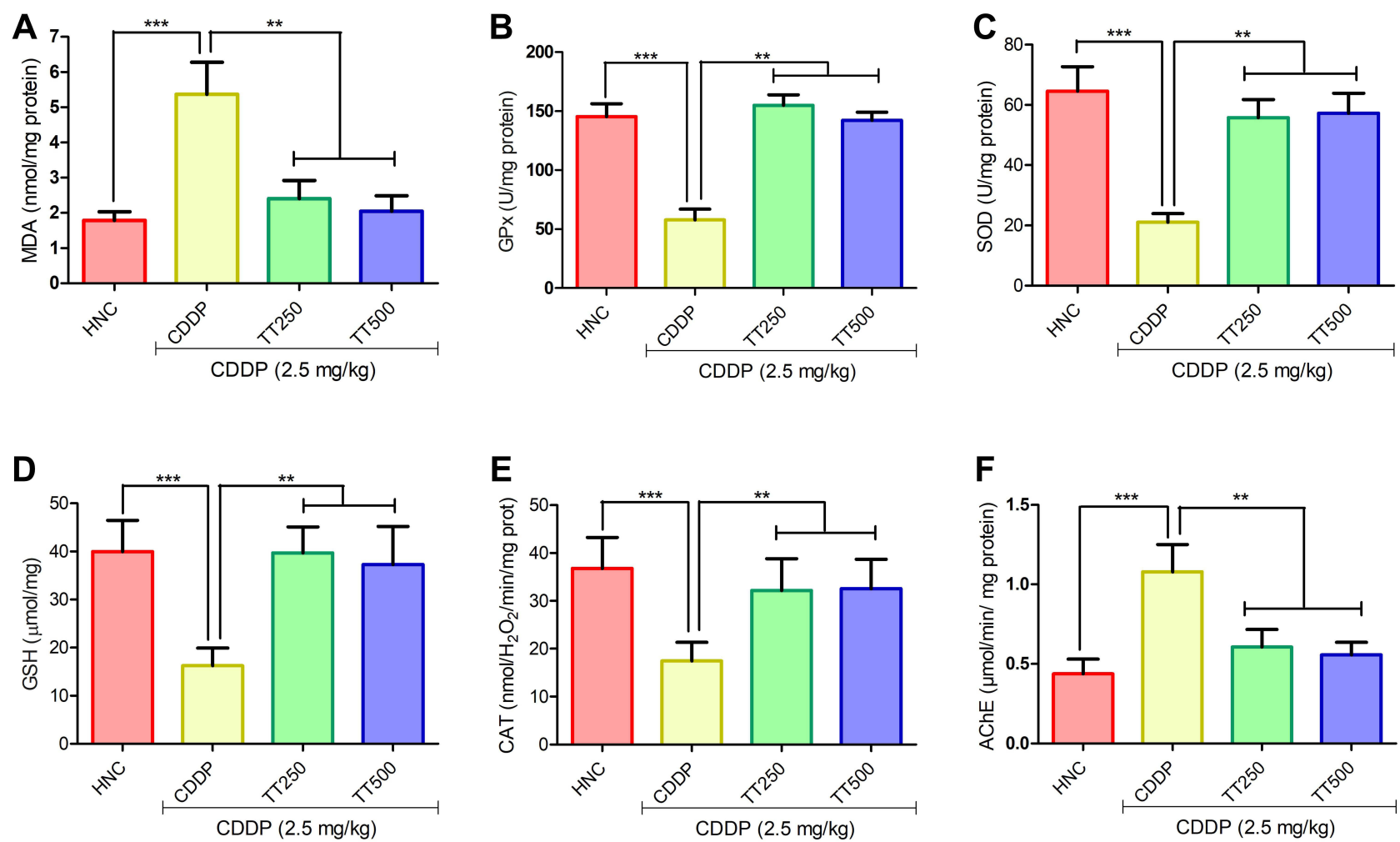

Figure 4 Effect of TT on brain oxidative stress biomarkers (A) MDA, (B) GPx, (C) SOD, (D) GSH, (E) CAT and (F) brain acetylcholinesterase activity in CDDP-induced neurotoxicity in rats. Results are expressed as mean $\pm S D(n=6)$ and analyzed using one-way ANOVA followed by Tukey's post hoc test. ${ }^{*} p<0.001$ indicates significant difference compared to HNC group; $*$ * $p<0.001$ indicates significant difference compared to CDDP group.

\section{TT Improved AChE Activity in the Brain}

\section{Tissue of Rats}

The AChE activity in the brain tissue of CDDP control rats was significantly increased in comparison with $\mathrm{HNC}$ group. Conversely, TT administration elicited marked improvement by reducing the activity of $\mathrm{AChE}$ in the brain of the treated rats $(p<0.001$; Figure $4 \mathrm{~F})$.

\section{TT Suppressed Biomarkers of Inflammation and Apoptosis}

As depicted in Figure 5, TNF- $\alpha$ level was significantly increased in the brain tissues of CDDP animals when compared with the HNC counterpart. IL- 6 and IL- $1 \beta$ levels were also observed to be markedly increased in the CDDP control group. The concentration of TNF- $\alpha$, IL- 6 and IL-1 $\beta$ were significantly reduced in comparison with CDDP control rats in the TT treated groups $(p<0.001$; Figure $5 \mathrm{~A}-\mathrm{C}$ ). In addition, CDDP significantly upregulated the concentration of caspase- 3 in the brain tissues of the CDDP control rats relative to the $\mathrm{HNC}$ group. Treatment with TT at 250 and $500 \mathrm{mg} / \mathrm{kg}$ significantly decreased the concentration of caspase- 3 in the brain tissues of treated rats compared to CDDP alone group (Figure 5D).

\section{TT Alleviated Pathological Damages in the Brain Tissues of Rats}

The histopathological results according to H\&E staining revealed normal brain architecture including neurons of variable sizes without any obvious indications of apoptosis and glial proliferation of the neurons. In contrast, the CDDP control rats showed obvious signs of neuronal apoptosis, inflammation of neuronal cells, disordered pyramidal cell layer as well as glial proliferation. Treatment with TT produced significant alleviation to the pathological alterations in the brain tissues of the treated rats (Figure 6A-D).

\section{Effect of TT on Immunostaining Intensity of $\mathrm{Bcl} 2$ and $\mathrm{p} 53$ Proteins}

The effect of TT on immunostaining intensity of Bcl 2 and p53 proteins are presented in Figures 7 and 8. Treatment with CDDP only showed reduced immunostaining intensity of $\mathrm{Bcl} 2$, whereas $\mathrm{p} 53$ protein immunostaining 

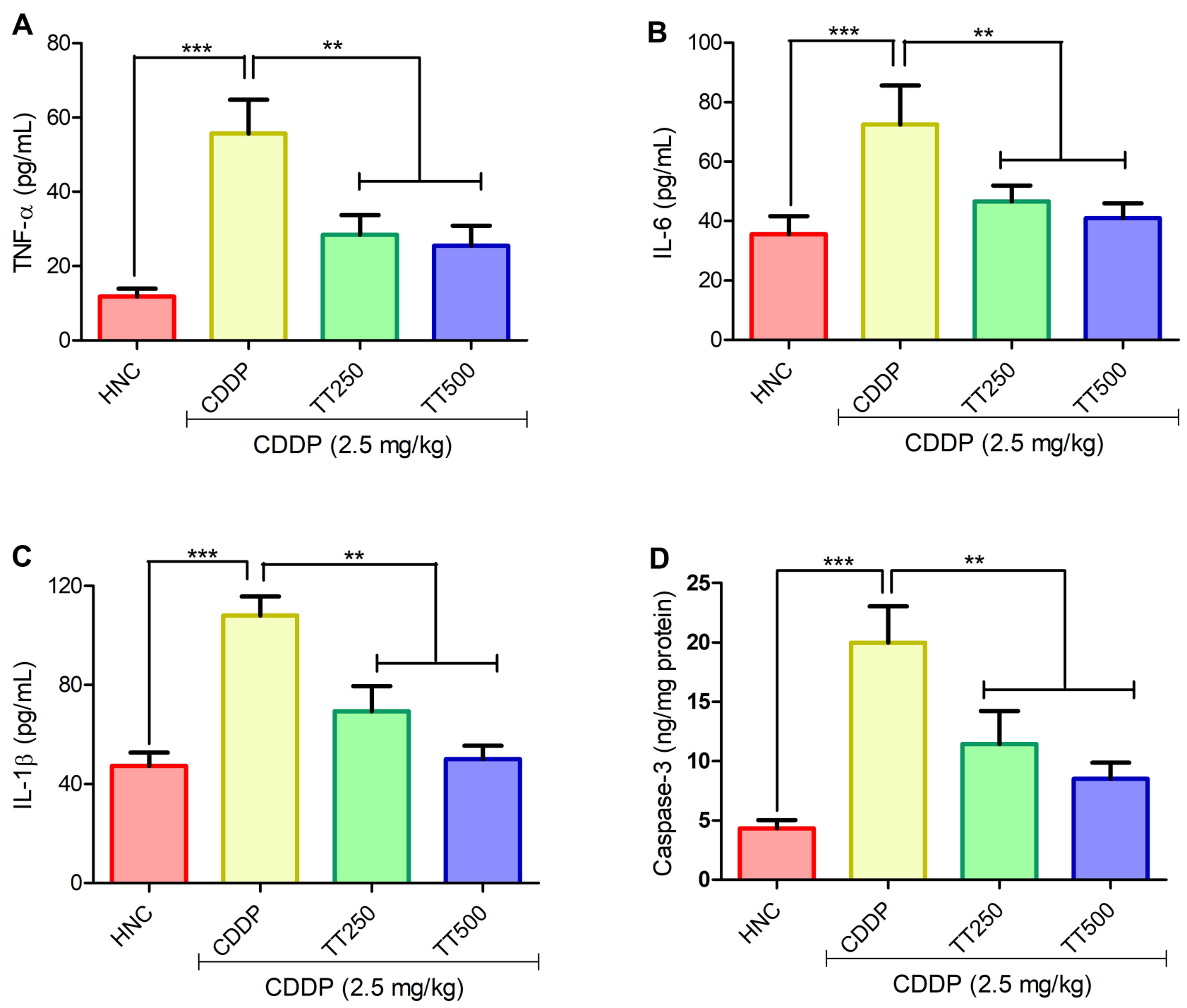

Figure 5 Effect of TT on brain proinflammatory cytokines (A) TNF- $\alpha$, (B) IL-6, (C) IL-I $\beta$ and (D) caspase-3 activity in CDDP induced neurotoxicity in rats. Results are expressed as mean $\pm S D(n=6)$ and analyzed using one-way ANOVA followed by Tukey post hoc test. ${ }^{*}<0.00$ I indicates significant difference compared to HNC group; $* * p<0.001$ indicates significant difference compared to CDDP group.

intensity increased (Figures 6 and 7). However, combined treatment with TT indicated significantly increased intensity for Bcl2 and reduced intensity for $\mathrm{p} 53$ in relation to CDDP control (Figures 6 and 7).

\section{UHPLC-DAD-ESI-QTOF-MS Profiling of TT}

The results of the phytochemical profiling of the bioactive compounds in TT extract using UHPLC-ESI-QTOF-MS/ MS analysis (negative mode) is shown in Table 1. The data revealed the presence of various classes of compounds majorly flavonoid and phenolic glycosides, including kaempferol-7 O-glucoside, isovitexin, luteolin 3'- methyl ether 7,4'-dixyloside, luteolin 6-C-glucoside 8-Carabinoside, okanin 4'-O-(4",6"-di-O-acetyl glucoside), cutellarein 7,4'-dirhamnoside and vestitone 7-glucoside. Other compounds such as nonglycosylated flavones including amentoflavone, a para-benzoquinone (embelin), fatty acids and coumarin derivative (esculetin) were also identified.

\section{Discussion}

Cisplatin (CDDP) is one of the leading anticancer agents in cancer chemotherapy. The consistent worry of clinicians about cisplatin use is the variegated side effects chiefly linked with neurotoxicity, nephrotoxicity, and testicular 
HNC

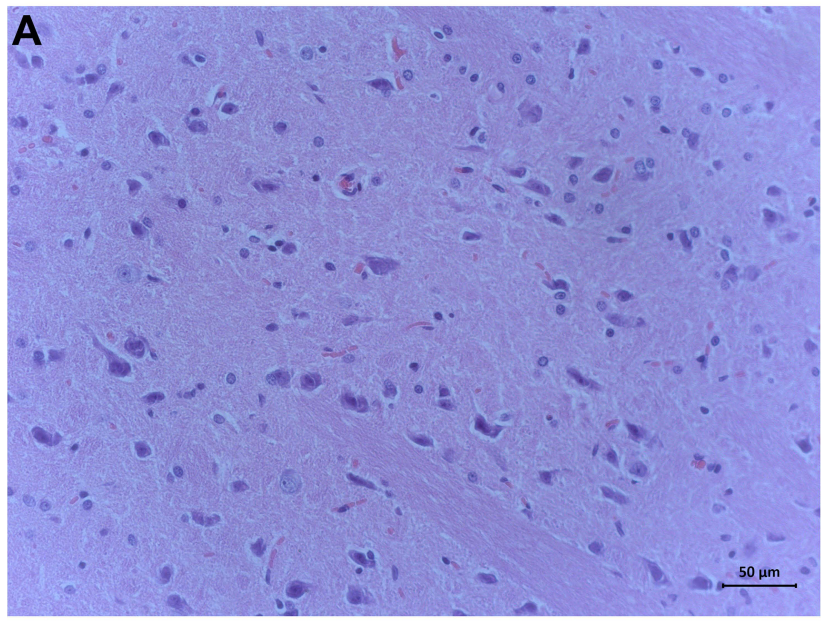

TT250

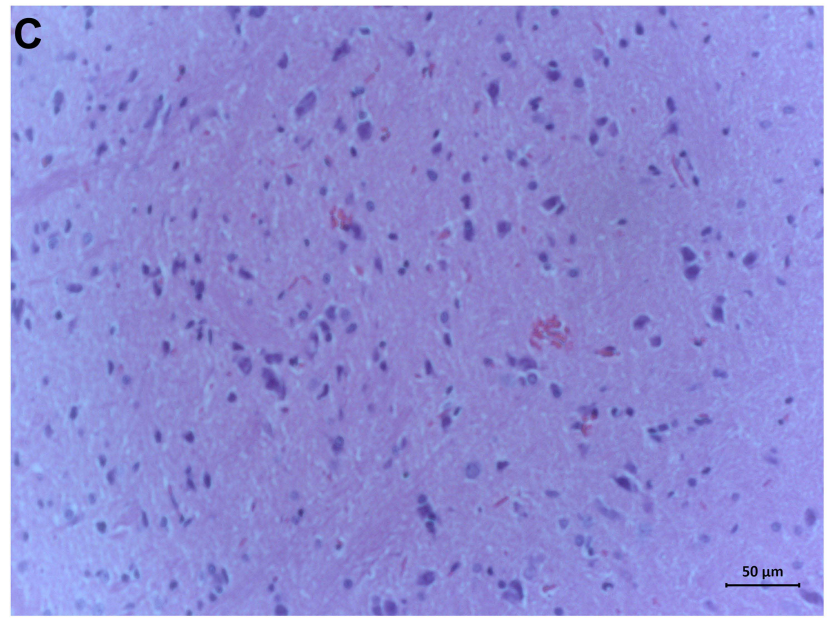

CDDP

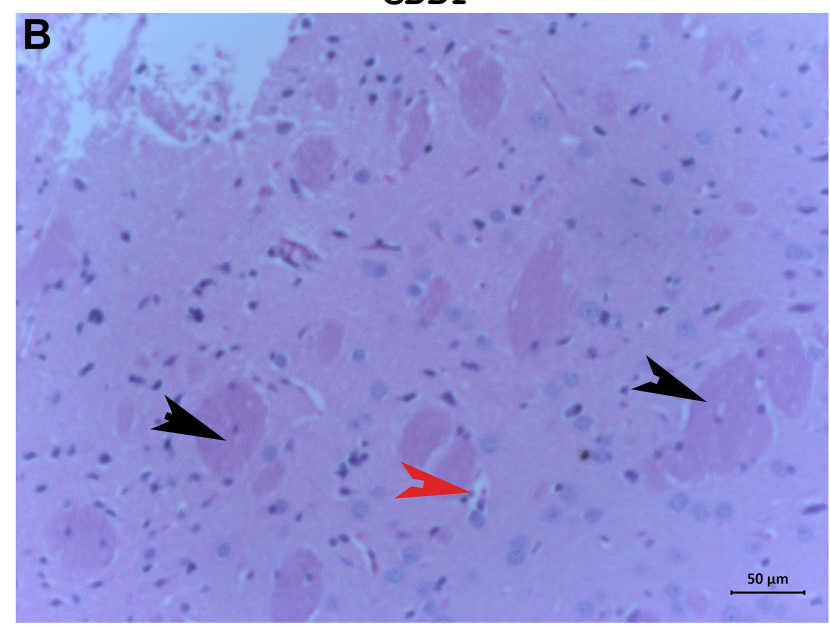

TT500

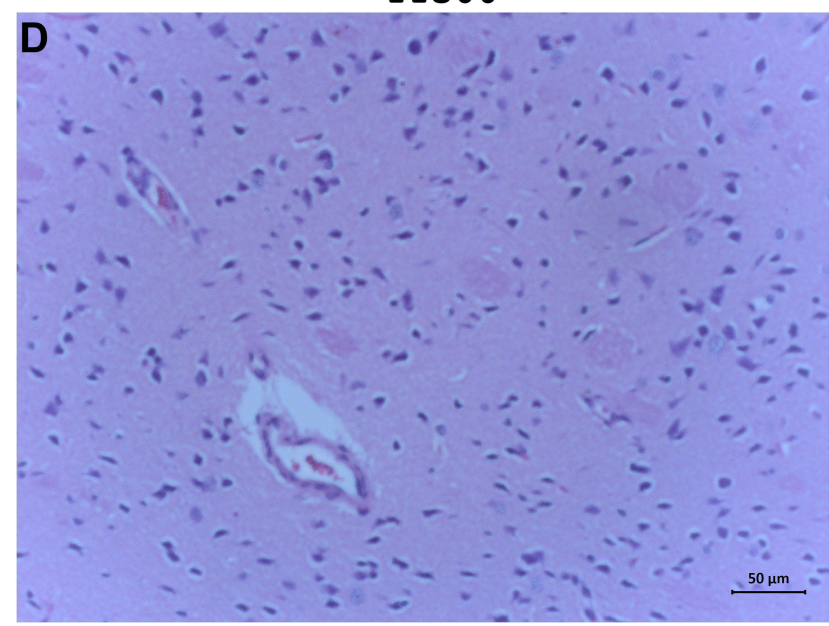

Figure 6 H\&E photomicrographs showing histology of brain tissues of (A) HNC, (B) CDDP, (C) TT250 and (D) TT500 groups, respectively. H\&E ×400.

damage. ${ }^{7,23,24}$ However, studies probing into the mechanisms of CDDP toxicity show that a network of oxidative stress, pro-inflammation and redox-mediated apoptosis play a pivotal role. ${ }^{25}$ Emerging research reports have revealed increasing interest for exploration of natural products to combat the integrated mechanism underlying the severe side effects of CDDP. We thus explored whether TT could mitigate CDDP neurotoxicity and to evaluate possible mechanism of action.

In this study, the intraperitoneal injection of CDDP at $2.5 \mathrm{mg} / \mathrm{kg}$ triggered significant loss of body weight in CDDP group compared to the normal control. Previous studies have also reported loss of body weight due to injection of CDDP. ${ }^{26,27}$ We observed that the intake of food by the rats reduced as well as the water intake. Conceivably, reduced food consumption occasioned by the CDDP may contribute to the loss of weight as energy expenditure may be greater than energy harvested during the reduced food intake. The study of Fulco et al suggests that CDDP causes metabolic dysfunction and inhibits citrate synthase contributing to depressed energy generation. ${ }^{28}$ The co-administration of TT was found to improve the food intake and consequently prevented loss of weight in TT + CDDP groups. Accumulating evidence depicts neurotoxicity and/or CICI as the overriding offtarget tissue toxicity of CDDP. ${ }^{29,30}$ Cisplatin is a potent penetrator of the blood-brain barrier, and so it can debilitate mature neurons to induce cognitive impairment and behavioral deficit. ${ }^{29,31}$ Cisplatin is clinically known to cause structural CNS mutilations which correlate with the cognitive deficits observed in CDDP-treated patient. ${ }^{23}$ Therefore, our study examined CICI and behavior of rats after CDDP injection via MWM and Y maze tests. Morris water-maze test is a very common behavioral model to test 
A

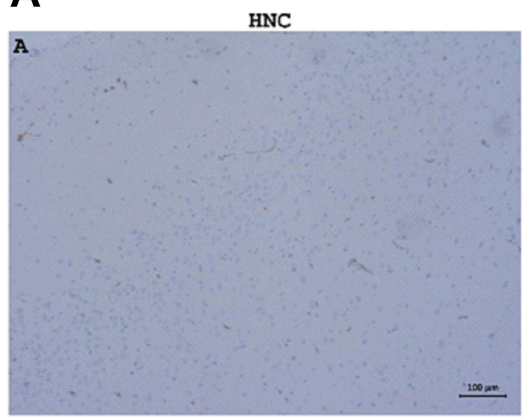

TT250

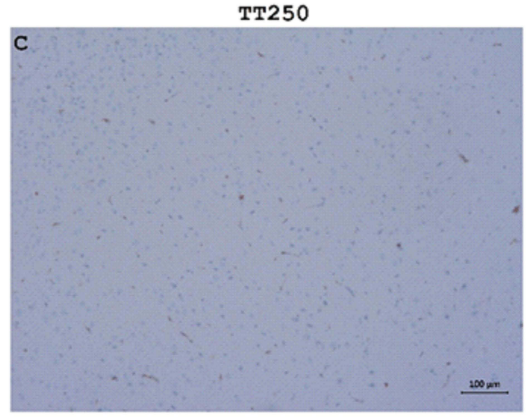

CDDP

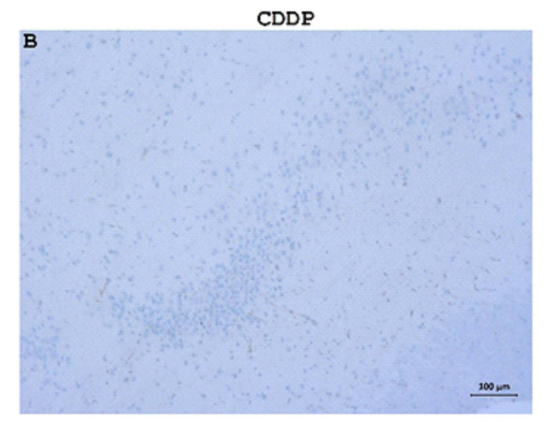

TT500

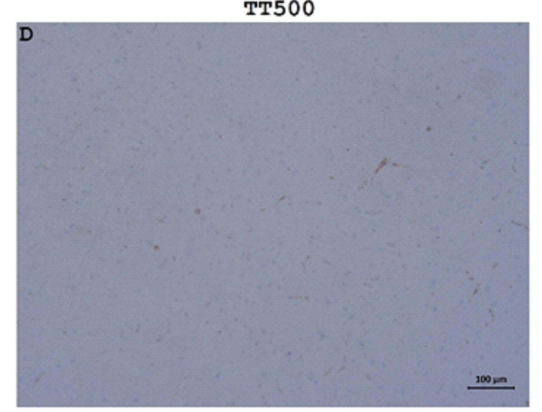

B

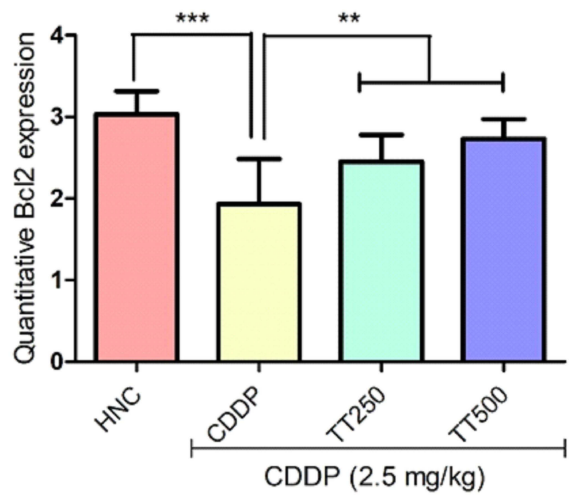

Figure 7 Effect of TT on immunostaining intensity for Bcl2 protein in CDDP induced neurotoxicity in rats. (A) Representative photomicrographs ( $\times 400)$ of Bcl2 immunohistochemistry of rat brain, (B) Quantitative expression of Bcl2. Results are expressed as mean \pm SD ( $n=6$ ) and analyzed using one-way ANOVA followed by Tukey's post hoc test. $*_{p}<0.00 \mathrm{I}$ indicates significant difference compared to HNC group; $* *<<0.00 \mathrm{I}$ indicates significant difference compared to CDDP group.

\section{A}
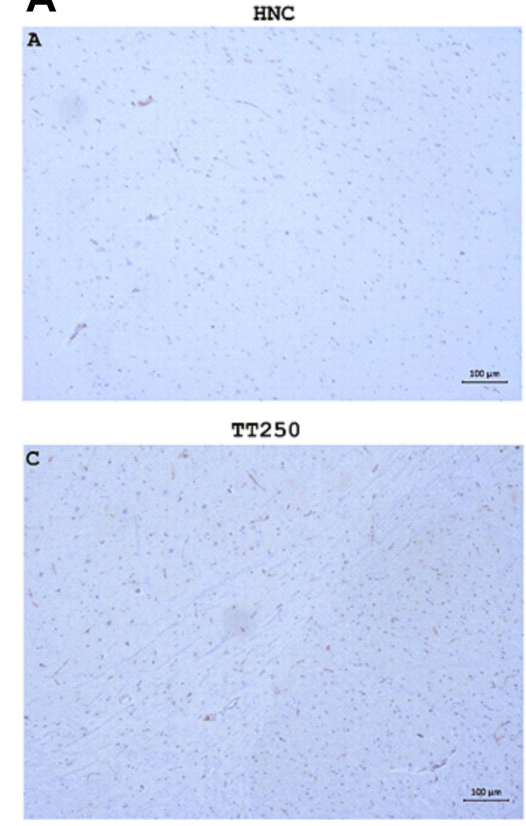

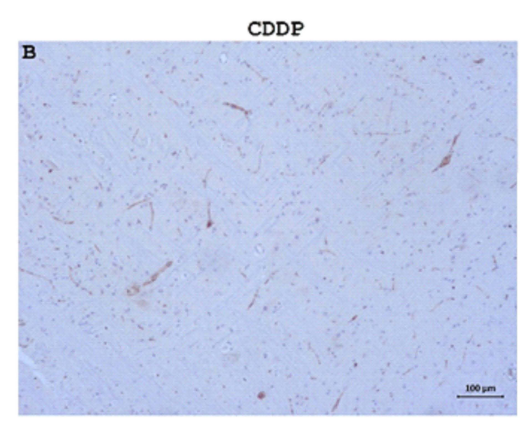

TT500

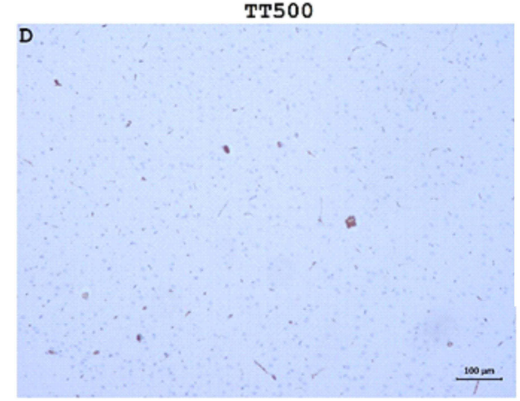

B

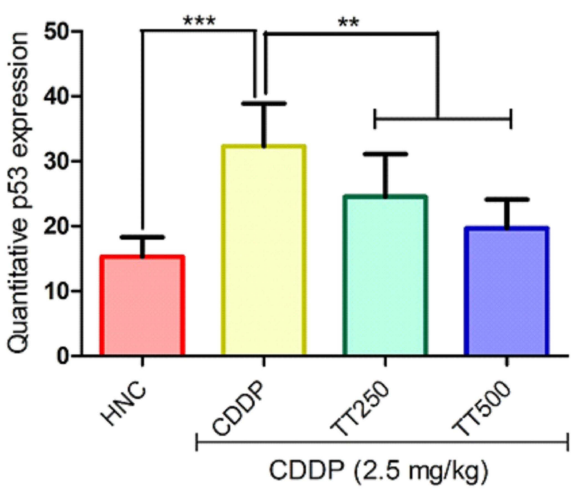

Figure 8 Effect of TT on immunostaining intensity for p53 protein in CDDP induced neurotoxicity in rats. (A) Representative photomicrographs $(\times 400)$ of $p 53$ immunohistochemistry of rat brain, (B) Quantitative expression of $p 53$. Results are expressed as mean $\pm S D(n=6)$ and analyzed using one-way ANOVA followed by Tukey's post hoc test. ${ }^{*} p<0.00$ I indicates significant difference compared to HNC group; ${ }^{* *} p<0.00$ I indicates significant difference compared to CDDP group.

rodent spatial memory and learning. ${ }^{32}$ The learning and memory exercise demonstrates that the CDDP adversely affected the rat brain such that there were considerable alterations in latency time and retention memory of rats compared to normal control rats. Furthermore, in the Y-maze test, the CDDP control rats showed significantly 


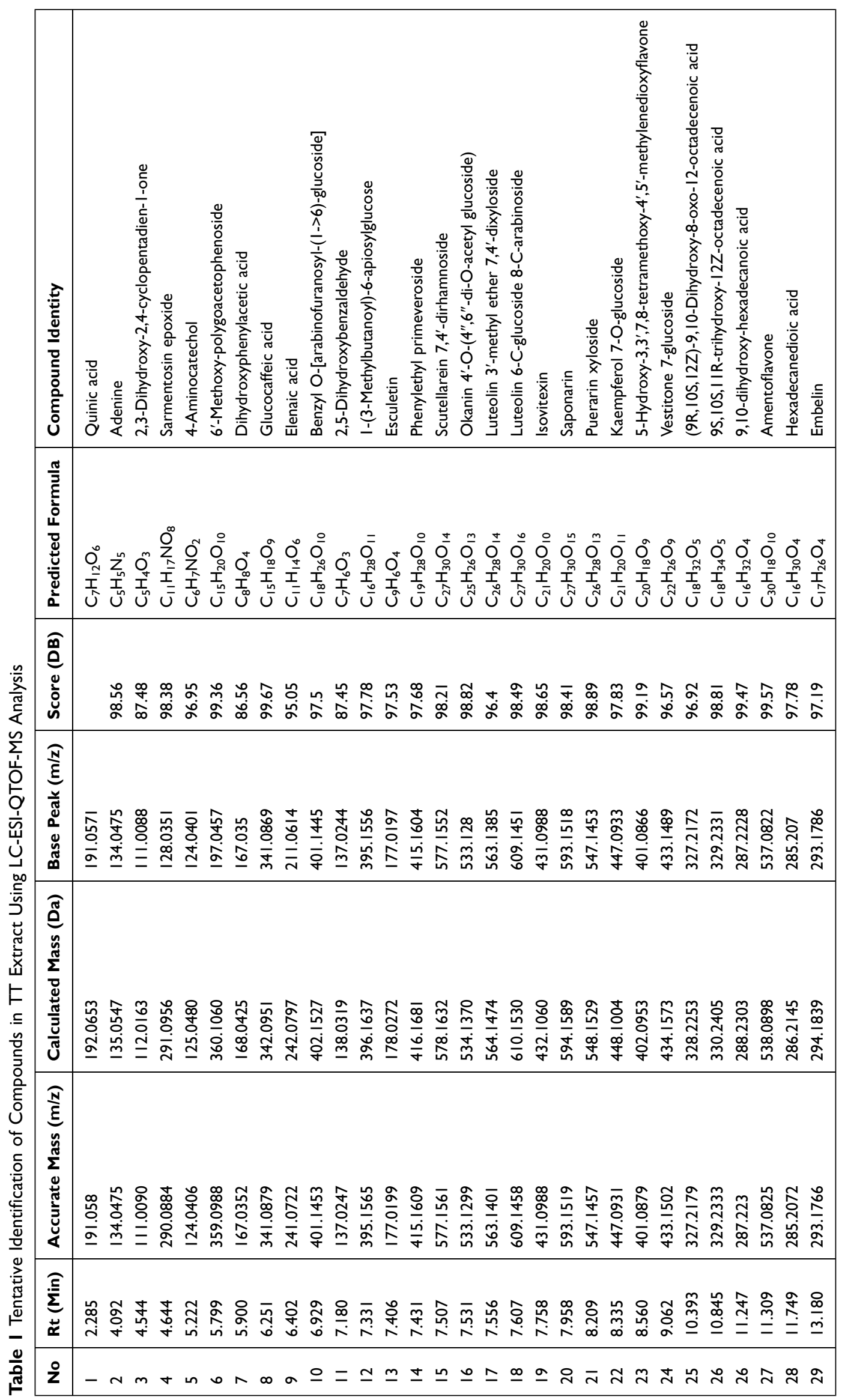


reduced spontaneous alternation compared to healthy normal control. However, Y-maze test assesses short-term hippocampus-dependent spatial working memory. ${ }^{33}$ Taken together herein, the tests suggest that the neurotoxic effect of CDDP reduced learning and memory capacity of the rats. This finding is consistent with our observation of the effect of CDDP on AChE activity in this study. In the CDDP control rats, the brain AChE activity markedly increased compared to normal control rats. ${ }^{34,35}$ This implies increased hydrolysis of acetylcholine, a crucial neurotransmitter involved in regulating cognitive function and cholinergic integrity. These findings are in consonance with the earlier investigations which demonstrated that CDDP treatment induced learning and memory dysfunctions in rats. ${ }^{36-38}$ In contrast, the rats in TT-treated groups showed significant improvement in latency time, retention memory and increase in the percentage spontaneous alternation when compared to the untreated CDDP control rats. It is noteworthy that the TT-250 treated group showed higher percentage spontaneous alternation than the TT500 treated group albeit not statistically different. TT inhibited the brain activity of $\mathrm{AChE}$ for restoration of cognitive integrity. Therefore, AChE inhibition may be pivotal to ameliorating CDDP side effect on the brain. The neuroprotective efficacy of TT in our study is consistent with reports in previous studies. In a systematic study of Phunchago et al, TT improves memory impairment, neurodegeneration and cholinergic disruption induced by ethanol. ${ }^{14}$ The study suggests that the HPLC-detected gallic acid, cyanidin, and quercetin may be responsible for the neuroprotective potential of TT. In a recent publication by Thong-asa and Bullangpoti, the neuroprotective potential of TT was observed against brain infarction and neuronal death in the cerebral cortex and hippocampus in a model of cerebral ischemia reperfusion. ${ }^{16}$

Publications have implicated oxidative stress as the leading contributor to the pathogenesis of CDDP-induced neurotoxicity. Redox imbalance orchestrates cellular machinery triggering DNA damage, inflammation and apoptosis. ${ }^{39,40}$ Cisplatin generates reactive oxygen species (ROS), including hydrogen peroxide and hydroxyl radicals which attack lipid membrane and inhibit antioxidant enzyme activity to promote lipid peroxidation and oxidative stress, respectively. ${ }^{29,41}$ In this study, the injected CDDP instigated preponderant elevations in the brain MDA levels in the CDDP model compared to the normal control. In addition, the brain activities of SOD, CAT, GSH, and GPx were also appreciably reduced compared to the normal control. In normal physiological interplay, cell antioxidant mechanisms modulate metabolic generation of ROS to maintain homeostasis. However, alterations to this milieu usually aggravate ROS generation. Herein, CDDP altered the milieu and increased ROS production leading to inhibition of SOD, GSH, CAT, and GPx activities and the consequent attack on brain cell membrane, hence, increased levels of MDA. Depressed activities of SOD and CAT may provoke accumulation of superoxide radical and hydrogen peroxide evolving further damage consistent with oxidative histopathological lesions found in the rat brain. Our findings regarding the aforementioned redox indices agreed with earlier reports on the oxidative effect of CDDP on the brain, kidney, and testis. ${ }^{7,23,39,42,43}$ It was interesting to observe that TT co-administration mitigated MDA release and significantly restored brain antioxidant defences dose dependently. Therefore, the beneficial health effect of TT in the current study demonstrates its antioxidant property and also support the reported action of TT in previous studies. ${ }^{14-16}$

The molecular mechanisms of CDDP neurotoxicity are multifactorial and complicated, consisting of oxidative stress, inflammation, apoptosis and autophagy leading to cell death. ${ }^{20,44}$ Accumulating evidence cleared that CDDP toxicity is a trigger of pro-inflammatory cascades through a significant decline in antioxidant mechanism. Meanwhile aberrant alterations in redoxinflammatory processes provoke apoptosis and autophagy by changes in signalling protein expression, including $\mathrm{Bcl} 2$ and $\mathrm{p53} .^{25,45,46}$ Our results depict that CDDP administration caused deteriorating pro-inflammation by considerable unregulation of pro-inflammatory cytokines, TNF- $\alpha$, IL- 6 and IL- $1 \beta$, in CDDP rats. Supportive evidence confirms that CDDP-induced oxidative stress-mediated activation of NF- $\kappa \mathrm{B}$ unlocks translation of nuclear TNF- $\alpha$, IL- 6 and IL- $1 \beta$ genes. ${ }^{43,47}$ Several studies have shown that injection of CDDP induces increased expression of NF- $\kappa \mathrm{B}, \mathrm{TNF}-\alpha$, IL-6 and IL-1 $\beta$ and other inflammatory mediators. ${ }^{24,29,43,47}$ The co-treatment with TT prevented overexpression of TNF- $\alpha$, IL-6 and IL-1 $\beta$ compared to the CDDP rats. Tiliacora triandra leaves and a Thai polyherbal remedy containing TT have been shown to possess anti-inflammatory effects. ${ }^{48,49}$

Studies indicate Bcl-2 family and the caspase family play an extremely important regulatory role in the apoptotic pathway. ${ }^{25}$ The expression of the antiapoptotic marker, Bcl2, was markedly reduced, while caspase- 3 and p53 
protein levels increased in CDDP rats. Cisplatin has been reported to reduce $\mathrm{Bcl} 2$ expression. ${ }^{44}$ The modulation of p53 determines the fate of stressed cells either by a cycle arrest or by removal of these cells by inducing apoptosis. ${ }^{45}$ The significant alterations in $\mathrm{Bcl} 2$ and caspase-3 expressions in our study suggest CDDP-induced brain apoptosis. These results suggest that CDDP evokes apoptosis in the brain of experimental rats confirming data in published papers. $^{25,29}$ Interestingly, TT alleviated these altered pathological expression.

Antioxidant compounds, particularly flavonoids and phenolics, are one of the most prevalent class of compounds identified in a vast number of plant species. These classes of compounds have been a source of extensive research over several decades due to their various pharmacological properties, especially in oxidative and inflammatory related disorders. ${ }^{50,51}$ Weerawatanakorn et al and Pasachan et al identified the presence of a high content of phenolic constituents in $T$. triandra leaves extract and these compounds were adjudged as the active principles showing antioxidant, anti-inflammatory and antidiabetic effects in their study. ${ }^{48,52}$ Our UHPLC-DADESI-QTOF-MS analysis of TT extract indicated the presence of phenolic and flavonoids, which may have accounted for the excellent antioxidant and anti-inflammatory effects against CDDP induced neurotoxicity. For instance Liu et al reported that isovitexin protected against CDDP induced renal injury via anti-inflammatory and antioxidative properties. ${ }^{53}$ Amentoflavone, a bioflavonoid tentatively identified in TT was reported to show antioxidant and anti-inflammatory effects. It was also reported to display neuroprotective properties including antidepressant and anxiolytic effects, and ameliorated scopolamineinduced memory via inhibition of AChE and increasing antioxidant enzyme activities. ${ }^{54}$ In addition, kaempferol 7O-glucoside and esculetin have also been reported as excellent antioxidant, anti-inflammatory, and neuroprotective agents. ${ }^{55-57}$

\section{Conclusion}

In conclusion, this study elucidated, for the first time, that TT can attenuate the neurotoxicity caused by CDDP via improving cognitive function and integrity associated with enhanced antioxidant defense mechanism, anti-inflammatory and antiapoptotic pathways. The protective effect of TT involves restoration of redox balance and suppression of AChE, TNF- $\alpha$, IL-6, IL-1 $\beta$ levels and apoptotic Bcl2/ caspase-3/p53.

\section{Acknowledgment}

This scientific work was supported by 2019 support program for outstanding young talents in colleges and universities of Anhui Province (gxyq2019190).

\section{Disclosure}

The authors report no conflicts of interest for this work.

\section{References}

1. Ongnok B, Chattipakorn N, Chattipakorn SC. Doxorubicin and cisplatin induced cognitive impairment: the possible mechanisms and interventions. Exp Neurol. 2020;324:113118. doi:10.1016/j. expneurol.2019.113118

2. Oun R, Moussa YE, Wheate NJ. The side effects of platinum-based chemotherapy drugs: a review for chemists. Dalton Trans. 2018;47:6645-6653. doi:10.1039/C8DT00838H

3. Stankovic JSK, Selakovic D, Mihailovic V, Rosic G. Antioxidant supplementation in the treatment of neurotoxicity induced by platinum-based chemotherapeutics-A review. Int $J$ Mol Sci. 2020;21:7753. doi:10.3390/ijms21207753

4. Falzone L, Salomone S, Libra M. Evolution of cancer pharmacological treatments at the turn of the third millennium. Front Pharmacol. 2018;9:1300. doi:10.3389/fphar.2018.01300

5. Zhou W, Kavelaars A, Heijnen CJ. Metformin prevents cisplatininduced cognitive impairment and brain damage in mice. PLoS One. 2016;11(3):e0151890. doi:10.1371/journal.pone.0151890

6. Kim SJ, Park C, Lee JN, Park R. Protective roles of fenofibrate against cisplatin-induced ototoxicity by the rescue of peroxisomal and mitochondrial dysfunction. Toxicol Appl Pharmacol. 2018;353:43-54. doi:10.1016/j.taap.2018.06.010

7. Wang L, He Y, Li Y, et al. Protective effects of nucleosides-rich extract from Cordyceps cicadae against cisplatin induced testicular damage. Chem Biodivers. 2020;11:e2000671.

8. Yin M, Li N, Makinde EA, Olatunji OJ, Ni ZN. N6-2-hydroxyethyladenosine ameliorate cisplatin induced acute kidney injury in mice. All Life. 2020;13:244-251. doi:10.1080/26895293.2020.1760149

9. Wang L, Apple AC, Schroeder MP, et al. Reduced prefrontal activation during working and long-term memory tasks and impaired patient-reported cognition among cancer survivors post chemotherapy compared with healthy controls. Cancer. 2016;122:258-268. doi:10.1002/cncr.29737

10. Chtourou Y, Gargouri B, Kebieche M, Fetoui H. Naringin abrogates cisplatin-induced cognitive deficits and cholinergic dysfunction through the down-regulation of AChE expression and iNOS signaling pathways in hippocampus of aged rats. $J$ Mol Neurosci. 2015;56 (2):349-362. doi:10.1007/s12031-015-0547-0

11. Salih NA, Al-Baggou BK. Effect of memantine hydrochloride on cisplatin-induced neurobehavioral toxicity in mice. Acta Neurol Belg. 2020;120(1):71-82. doi:10.1007/s13760-019-01161-z

12. Makinde EA, Radenahmad N, Adekoya AE, Olatunji OJ. Tiliacora triandra extract possesses antidiabetic effects in high fat diet/streptozotocin-induced diabetes in rats. J Food Biochem. 2020;44(6): e13239. doi:10.1111/jfbc.13239

13. Makinde EA, Ovatlarnporn C, Adekoya AE, Nwabor OF, Olatunji OJ. Antidiabetic, antioxidant and antimicrobial activity of the aerial part of Tiliacora triandra. S Afr J Bot. 2019;125:337-343. doi:10.1016/j.sajb.2019.08.012

14. Phunchago N, Wattanathorn J, Chaisiwamongkol K. Tiliacora triandra, an anti-intoxication plant, improves memory impairment, neurodegeneration, cholinergic function, and oxidative stress in hippocampus of ethanol dependence rats. Oxid Med Cell Longev. 2015;2015:918426. doi:10.1155/2015/918426 
15. Song P, Sun C, Li J, et al. Tiliacora triandra extract and its major constituent attenuates diabetic kidney and testicular impairment by modulating redox imbalance and pro-inflammatory responses in rats. J Sci Food Agric. 2021;101:1598-1608. doi:10.1002/jsfa.10779

16. Thong-Asa W, Bullangpoti V. Neuroprotective effects of Tiliacora triandra leaf extract in a mice model of cerebral ischemia reperfusion. Avicenna J Phytomed. 2020;10:202-212.

17. Thong-Asa W, Tumkiratiwong P, Bullangpoti V, Kongnirundonsuk K, Tilokskulchai K. Tiliacora triandra (Colebr.) Diels leaf extract enhances spatial learning and learning flexibility and prevents dentate gyrus neuronal damage induced by cerebral ischemia/reperfusion injury in mice. Avicenna J Phytomed. 2017;7:389-400.

18. Liu C, Ma M, Wen C, Uz Zaman R, Olatunji OJ. Antiallodynic and anti-hyperalgesia effects of Tiliacora triandra against cisplatininduced peripheral neuropathy. All Life. 2021;14:441-449. doi:10.1080/26895293.2021.1927204

19. Chen X, Famurewa AC, Tang J, Olatunde OO, Olatunji OJ. Hyperoside attenuates neuroinflammation, cognitive impairment and oxidative stress via suppressing $\mathrm{TNF}-\alpha / \mathrm{NF}-\kappa \mathrm{B} /$ caspase- 3 signaling in type 2 diabetes rats. Nutr Neurosci. 2021;16:1-11. doi:10.1080/ 1028415X.2021.1901047

20. Wall PM, Messier C. Infralimbic kappa opioid and muscarinic M1 receptor interactions in the concurrent modulation of anxiety and memory. Psychopharmacology. 2002;160:233-244. doi:10.1007/ s00213-001-0979-9

21. Ellman GL. Tissue sulfhydryl groups. Arch Biochem Biophys. 1959;82:70-77. doi:10.1016/0003-9861(59)90090-6

22. Ahmad ST, Arjumand W, Seth A, et al. Preclinical renal cancer chemopreventive efficacy of geraniol by modulation of multiple molecular pathways. Toxicol. 2011;290:69-81. doi:10.1016/j. tox.2011.08.020

23. El-Deeb OS, Soliman GM, Elesawy RO. Linagliptin, the dipeptidyl peptidase-4 enzyme inhibitor, lessens CHOP and GRP78 biomarkers levels in cisplatin-induced neurobehavioral deficits: a possible restorative gateway. $J$ Biochem Mol Toxicol. 2020;34:e22541. doi:10.1002/jbt.22541

24. Park YJ, Kim KS, Park JH, et al. Protective effects of dendropanoxide isolated from Dendropanax morbifera against cisplatin-induced acute kidney injury via the AMPK/mTOR signaling pathway. Food Chem Toxicol. 2020;145:111605. doi:10.1016/j.fct.2020.111605

25. Chen X, Wei W, Li Y, Huang J, Ci X. Hesperetin relieves cisplatininduced acute kidney injury by mitigating oxidative stress, inflammation and apoptosis. Chem Biol Interact. 2019;308:269-278. doi:10.1016/j.cbi.2019.05.040

26. Potočnjak I, Marinić J, Batičić L, Šimić L, Broznić D, Domitrović R. Aucubin administered by either oral or parenteral route protects against cisplatin-induced acute kidney injury in mice. Food Chem Toxicol. 2020;142:111472. doi:10.1016/j.fct.2020.111472

27. Famurewa AC, Ekeleme-Egedigwe CA, Onwe CS, et al. Ginger juice prevents cisplatin-induced oxidative stress, endocrine imbalance and $\mathrm{NO} / \mathrm{iNOS} / \mathrm{NF}-\kappa \mathrm{B}$ signalling via modulating testicular redox-inflammatory mechanism in rats. Andrologia. 2020;52:e13786. doi:10.1111/ and 13786

28. Fulco BC, Jung JT, Brum LO, Zborowski VA, Goulart TA, Nogueira CW. Similar hepatoprotective effectiveness of Diphenyl diselenide and Ebselen against cisplatin-induced disruption of metabolic homeostasis and redox balance in juvenile rats. Chem Biol Interact. 2020;330:109234. doi:10.1016/j.cbi.2020.109234

29. Gomaa DH, Hozayen WG, Al-shafeey H, Elkelawy AM, Hashem KS. Ginkgo biloba alleviates cisplatin-mediated neurotoxicity in rats via modulating APP/A/P2X7R/P2Y12R and XIAP/BDNF-dependent caspase-3 apoptotic pathway. Appl Sci. 2020;10:4786-4801. doi:10.3390/app10144786

30. Sałat K. Chemotherapy-induced peripheral neuropathy: part 1-current state of knowledge and perspectives for pharmacotherapy. Pharmacol Rep. 2020;72:486-507. doi:10.1007/s43440-020-00109-y
31. Seigers R, Schagen S, Van Tellingen O, Dietrich J. Chemotherapyrelated cognitive dysfunction: current animal studies and future directions. Brain Imaging Behav. 2013;7:453-459. doi:10.1007/s11682013-9250-3

32. Morris RG, Garrud P, Rawlins JA, O'Keefe J. Place navigation impaired in rats with hippocampal lesions. Nature. 1982;297:681683. doi:10.1038/297681a0

33. Hao R, Song X, Li F, Tan X, Sun-Waterhouse D, Li D. Caffeic acid phenethyl ester reversed cadmium-induced cell death in hippocampus and cortex and subsequent cognitive disorders in mice: involvements of AMPK/SIRT1 pathway and amyloid-tau-neuroinflammation axis. Food Chem Toxicol. 2020;144:111636. doi:10.1016/j.fct.2020.111636

34. Wachiryah T, Hathaipat L. Enhancing effect of Tiliacora triandra leaves extract on spatial learning, memory and learning flexibility as well as hippocampal choline acetyltransferase activity in mice. Avicenna J Phytomed. 2018;8:380-388.

35. Ingkaninan K, Temkitthawon P, Chuenchom K, Yuyaem T, Thongnoi W. Screening for acetylcholinesterase inhibitory activity in plants used in Thai traditional rejuvenating and neurotonic remedies. $J$ Ethnopharmacol. 2003;89:261-264. doi:10.1016/j.jep.2003.08.008

36. Kandeil MA, Gomaa SB, Mahmoud MO. The effect of some natural antioxidants against cisplatin-induced neurotoxicity in rats: behavioral testing. Heliyon. 2020;6:e04708. doi:10.1016/j.heliyon.2020. e04708

37. Abdelkader NF, Saad MA, Abdelsalam RM. Neuroprotective effect of nebivolol against cisplatin-associated depressive-like behavior in rats. $J$ Neurochem. 2017;141:449-460. doi:10.1111/jnc.13978

38. Oz M, Atalik KE, Yerlikaya FH, Demir EA. Curcumin alleviates cisplatin-induced learning and memory impairments. Neurobiol Learn Mem. 2015;123:43-49. doi:10.1016/j.nlm.2015.05.001

39. Eren H, Mercantepe T, Tumkaya L, et al. Evaluation of the protective effects of amifostine and melatonin against cisplatin induced testis injury via oxidative stress and apoptosis in rats. Exp Mol Pathol. 2020;112:104324. doi:10.1016/j.yexmp.2019.104324

40. Ueki M, Ueno M, Morishita J, Maekawa N. Curcumin ameliorates cisplatin-induced nephrotoxicity by inhibiting renal inflammation in mice. $J$ Biosci Bioeng. 2013;115:547-551. doi:10.1016/j.jbiosc.2012.11.007

41. Famurewa AC, Edeogu CO, Offor FI, Besong EE, Akunna GG, Maduagwuna EK. Downregulation of redox imbalance and iNOS/ NF-KB/caspase-3 signalling with zinc supplementation prevents urotoxicity of cyclophosphamide-induced hemorrhagic cystitis in rats. Life Sci. 2021;266:118913. doi:10.1016/j.lfs.2020.118913

42. Sohail N, Hira K, Kori JA, et al. Nephroprotective effect of ethanol extract and fractions of a sea lettuce, Ulva fasciata against cisplatininduced kidney injury in rats. Environ Sci Pollut Res Int. 2021;28:9448-9461. doi:10.1007/s11356-020-11321-x

43. Yarijani ZM, Godini A, Madani SH, Najafi H. Reduction of cisplatininduced renal and hepatic side effects in rat through antioxidative and antiinflammatory properties of Malva sylvestris L. extract. Biomed Pharmacother. 2018;106:1767-1774. doi:10.1016/j.biopha.2018.07.115

44. Abdel-Razek EA, Abo-Youssef AM, Azouz AA. Benzbromarone mitigates cisplatin nephrotoxicity involving enhanced peroxisome proliferator-activated receptor-alpha (PPAR- $\alpha$ ) expression. Life Sci. 2020;243:117272. doi:10.1016/j.lfs.2020.117272

45. Domitrovic R, Cvijanovic O, Šušnic V, Katalinic N. Renoprotective mechanisms of chlorogenic acid in cisplatin-induced kidney injury. Toxicology. 2014;324:98-107. doi:10.1016/j.tox.2014.07.004

46. Kaygusuzoglu E, Caglayan C, Kandemir FM, et al. Zingerone ameliorates cisplatin-induced ovarian and uterine toxicity via suppression of sex hormone imbalances, oxidative stress, inflammation and apoptosis in female Wistar rats. Biomed Pharmacother. 2018;102:517530. doi:10.1016/j.biopha.2018.03.119

47. Hu J, Yang J, Jiang S, et al. Panax quinquefolium saponins protect against cisplatin evoked intestinal injury via ROS-mediated multiple mechanisms. Phytomedicine. 2021;82:153446. doi:10.1016/j. phymed.2020.153446 
48. Weerawatanakorn M, Rojsuntornkitti K, Pan M, Wongwaiwech D. Some phytochemicals and anti-inflammation effect of juice from Tiliacora triandra leaves. J Food Nutr Res. 2018;6:32-38. doi:10.12691/jfnr-6-1-6

49. Juckmeta T, Itharat A. Anti-inflammatory and antioxidant activities of Thai traditional remedy called ya-ha-rak. J Health Res. 2012;26:205-210.

50. Arfaoui L. Dietary plant polyphenols: effects of food processing on their content and bioavailability. Molecules. 2021;26(10):2959. doi:10.3390/molecules26102959

51. Hano C, Tungmunnithum D. Plant polyphenols, more than just simple natural antioxidants: oxidative stress, aging and age-related diseases. Medicines. 2020;7:26. doi:10.3390/medicines7050026

52. Pasachan T, Duangjai A, Ontawong A, et al. Tiliacora triandra (Colebr.) Diels leaf aqueous extract inhibits hepatic glucose production in HepG2 cells and type 2 diabetic rats. Molecules. 2021;26: 1239. doi: $10.3390 /$ molecules 26051239

53. Liu S, Zhang X, Wang J. Isovitexin protects against cisplatin-induced kidney injury in mice through inhibiting inflammatory and oxidative responses. Int Immunopharmacol. 2020;83:106437. doi:10.1016/j. intimp.2020.106437
54. Yu S, Yan H, Zhang L, et al. A review on the phytochemistry, pharmacology, and pharmacokinetics of amentoflavone, a naturallyoccurring biflavonoid. Molecules. 2017;22:299. doi:10.3390/ molecules22020299

55. Wang J, Fang X, Ge L, et al. Antitumor, antioxidant and anti-inflammatory activities of kaempferol and its corresponding glycosides and the enzymatic preparation of kaempferol. PLoS One. 2018;13: e0197563. doi:10.1371/journal.pone.0197563

56. Pruccoli L, Morroni F, Sita G, Hrelia P, Tarozzi A. Esculetin as a bifunctional antioxidant prevents and counteracts the oxidative stress and neuronal death induced by amyloid protein in SH-SY5Y cells. Antioxidants. 2020;9:551. doi:10.3390/antiox9060551

57. Zhu L, Nang C, Luo F, et al. Esculetin attenuates lipopolysaccharide (LPS)-induced neuroinflammatory processes and depressive-like behavior in mice. Physiol Behav. 2016;163:184-192. doi:10.1016/j. physbeh.2016.04.051
Journal of Inflammation Research

\section{Publish your work in this journal}

The Journal of Inflammation Research is an international, peerreviewed open-access journal that welcomes laboratory and clinical findings on the molecular basis, cell biology and pharmacology of inflammation including original research, reviews, symposium reports, hypothesis formation and commentaries on: acute/chronic inflammation; mediators of inflammation; cellular processes; molecular
Dovepress

mechanisms; pharmacology and novel anti-inflammatory drugs; clinical conditions involving inflammation. The manuscript management system is completely online and includes a very quick and fair peerreview system. Visit http://www.dovepress.com/testimonials.php to read real quotes from published authors. 